\title{
Infant Mortality Decline In Zambia: To What Extent Did Maternal Education Influence Infant Mortality Rate Decline For The Period 1992 To 2018?
}

Johnathan Halinga ( $\boldsymbol{\sim}$ johalinga@gmail.com )

University of Zambia

Chabila Mapoma

University of Zambia

\section{Research Article}

Keywords: Infant Mortality, Maternal Education, Trend Analysis, Infant Mortality Decline, Influence

Posted Date: May 26th, 2021

DOI: https://doi.org/10.21203/rs.3.rs-493349/v1

License: (a) (i) This work is licensed under a Creative Commons Attribution 4.0 International License. Read Full License 


\section{Abstract}

Background: In Zambia, infant mortality has reduced from 107 to 42 per 1000 live births from 1992 to 2018. Across the Globe, it is argued that maternal education contributes to the reduction in infant mortality. However, the extent to which maternal education influenced the decline in infant mortality in Zambia for the period 1992 to 2018 was not clear. Therefore, this study investigated the extent to which maternal education influenced the decline in infant mortality in Zambia from 1992 to 2018. The purpose of this study is to inform policy as well as program planning and implementation in the promotion of infant survival.

Methods: This study was a secondary data analysis (Trend Analysis). Zambia Demographic and Health Survey (ZDHS) data sets: 1992 to 2018 were used in the analyses. The unit of analysis was infant mortality with sample sizes: 6169, 7066, 6526, 6025,12916 and 9959 respectively. All analyses were done using the statistical package for social sciences version 25.0. Univariate analysis was done for descriptive statistics. Chi-square was used for testing associations. Point Bi-serial correction was done between maternal education and infant mortality at $1 \%$ and/or $5 \%$ levels of significance. Binary logistic regression was used to determine the influence of predictors on infant mortality.

Results: Maternal education was (negatively) related to infant mortality from 1992 to 2001-2. The correlation coefficients were smaller negatives indicating a very weak negative relationship between maternal education and infant mortality. Among the interactions, only the interactions between maternal education and contraceptive use, preceding birth interval, breast feeding, and antenatal care (visits) significantly influenced the decline in infant mortality from 1992 to 2018. Singularly, maternal education influenced the decline in infant mortality rate to a lesser extent (only marginally). When interacted with contraceptive use, preceding birth interval, breast feeding and antenatal care, maternal education influenced the decline in infant mortality to a larger extent.

Conclusion: For more robust interventions to further reduce infant mortality in the country, these interactions should be considered in the planning and implementation of child health programs such as the child health nutrition, national partnership for maternal, new-born and child health.

\section{Background}

Infant mortality (IM) is the term used to describe any deaths arising in children who are born alive but die before their first birthday (1). Infant mortality is said to be a sensitive measure of the overall health of a population as it reflects the apparent association between the causes and other factors that are likely to influence the health status of whole populations. These include factors such as economic development, general living conditions, social well-being, rates of illness, and the quality of the environment in which they live (2). Infant mortality rate is exceedingly responsive to changes in these factors and as such, it is said to be an important index of economic development and social-health status of every society (2). Globally, infant mortality has decreased from an estimated rate of 65 deaths per 1000 live births in 1990 to about 29 deaths per 1000 live births in 2017. In addition, annual infant deaths have declined from 8.8 million in 1990 to 4.1 million in 2017 (3). Sub-Saharan Africa (SSA) continues to record the highest levels of infant deaths and this therefore, calls for more efforts from African governments including Zambia, to effectively invest in infant mortality reduction (4). In Zambia, IM reduced by $57.9 \%$ (107 to 42 per 1000 live births) from 1992 to 2018. See Figure 1.

\section{Infant Mortality Trend: Zambia (ZDHS: 1992 to 2018)}

Figure 1 shows the trends in the decline of infant mortality in Zambia from 1992 to 2018.

\section{Source: (ㅁ).}

One important ingredient in the reduction of infant mortality is maternal education (6). Maternal education is internationally recognized as one of the strongest determinants of infant survival in developing countries, and mass primary education for women is a common policy recommendation to improve infant health in developing countries (7-9).

Most demographic research indicates that there is a strong association between maternal education and infant mortality (10-11). These findings have led some researchers, including Caldwell, to conclude that there is a causal relationship between mothers' education and infant mortality. However, other researchers, (12) reject the existence of a strong causal relationship arguing that the nature of disease to which the children are exposed during the first year of life is such that mothers (whether educated or not) cannot do much to prevent the deaths of their infants. Therefore, the causal relationship between ME and IM remained unclear.

Infant mortality remains a big problem in Zambia (5). The government of Zambia and several Non-Governmental Organizations (NGOs) such as Campaign for Female Education (CAMFED) are investing in the education of girls and consequently, ME has been improving since 1992 to date, with many more women attaining tertiary education (5). See Table 
Table1: Trends in Maternal Education: Zambia (ZDHS: 1992 to 2018)

\begin{tabular}{|c|c|c|c|c|c|c|c|c|c|c|c|}
\hline \multirow[t]{2}{*}{ Year } & \multicolumn{2}{|l|}{1992} & \multicolumn{2}{|l|}{1996} & \multicolumn{2}{|c|}{ 2001-2002 } & \multicolumn{2}{|l|}{2007} & \multicolumn{2}{|c|}{ 2013-2014 } & \multirow{2}{*}{$\begin{array}{l}2018 \\
\begin{array}{l}\text { Women } \\
\%\end{array}\end{array}$} \\
\hline & Women & $\%$ & Women & $\%$ & Women & $\%$ & Women & $\%$ & Women & $\%$ & \\
\hline \multicolumn{12}{|l|}{ Education Level } \\
\hline No Education & 1217 & 16.3 & 1093 & 14.3 & 925 & 12.1 & 744 & 10.4 & 1,375 & 8.4 & $\begin{array}{l}1054 \\
7.7 \%\end{array}$ \\
\hline Primary & 4443 & 59.4 & 5033 & 65.7 & 4439 & 58.0 & 3,891 & 54.4 & 7,685 & 46.8 & $\begin{array}{l}6059 \\
44.3 \%\end{array}$ \\
\hline Secondary & 1654 & 22.2 & 2130 & 27.8 & 2061 & 26.9 & 2,140 & 29.9 & 6,521 & 39.7 & $\begin{array}{l}5816 \\
42.5 \%\end{array}$ \\
\hline Tertiary & 154 & 2.1 & 230 & 3 & 234 & 3.1 & 371 & 5.2 & 830 & 5.1 & $\begin{array}{l}755 \\
5.5 \%\end{array}$ \\
\hline
\end{tabular}

\section{Source: (5)}

However, the extent to which ME influenced the decline in IM in Zambia from 1992 to 2018 was not known. This study therefore, investigated the extent to which ME influenced the decline in IM from 1992 to 2018 . The paper investigated the relationship between ME and IM and examined how the interactions between ME and selected social-economic, demographic, mother and child health and water and sanitation factors influenced the decline in IM during the period 1992 to 2018.

\section{Data And Methods}

The study design adopted in this study was a secondary analysis (trend analysis). This study employed the ZDHS kids' records data sets for the years 1992, 1996, 2001/02, 2007, 2013-14 and 2018 in the analyses. The outcome variable (Unit of analysis) was infant mortality extracted using variables; B3- Date of birth, B5-Child is alive, B7-Age at death in months, V008-Date of interview, by use of the predictive software; SPSS vision 25.0. Each woman (15-49) provided the information for her infant (s) as to whether the infant/infants died between age 0 and 1 year. This study only included infants who died within the first twelve month of life for the purpose of capturing infant mortality. The sample sizes for all the surveys were: $6169,7066,6526,6,025,12916$ and 9957 respective to the ZDHS years. The selected independent variables were grouped into four macro categories: socio-economic, demographic, mother and child health and water and sanitation. However, the key independent variable in this study was maternal education. Methods of analysis used were univariate, bivariate and multivariate. However, this paper only presents part of the Bivariate and the second and third models of multivariate analyses. At bivariate level Pearson Point Bi-Serial Correlation was done between ME in single years and the dependent variable to examine how it correlated with IM from 19192 to 2018. Binary logistic regression was used to determine the influence of all the predictors on the outcome variable. Data were weighted, checked for consistence with census data and a multicolineality test was performed to check for redundance among the predictor variables. The Mosley and Chain (11) child survival conceptual framework was adapted to underpin the analyses performed in this study. The study was ethically cleared by all relevant bodies.

\section{The Model}

Binary logistic regression was used to estimate the (Log Odds) of a child dying before reaching one year of age. The binary logistic regression equation was estimated as below:

$\operatorname{Logit}(P)=b_{0}+b_{1} X_{1}+b_{2} X_{2}+b_{3} X_{3}+\ldots .+b_{p} X_{p}+E$

P: - denotes the probability of the risk of infant mortality.

Where $\mathrm{P}$ is a dichotomous dependent variable with values 0 (did not die before the first birthday) or 1 (died before first birthday)

$\mathbf{b}_{1} \ldots \mathbf{b}_{\mathbf{p}}$ : - denotes the coefficients of the independent variables. 
$\mathbf{X}_{\mathbf{1}} \ldots \mathbf{X}_{\mathbf{p}}$ : - denotes the independent variables. All dichotomous variables were converted into dummies before they could be entered in the model. The model was built using the Enter Method in which all the predictors were entered at once regardless of whether they were significant or not.

\section{Results}

\section{Bivariate Analysis}

A Correlation Test Between ME in Single Years and IM was done to determine how infant mortality correlated with ME single years for the period 1992 to 2018 using point-biserial correlation at 0.01 or 0.05 levels of significance.

Table 2: Pearson Point-biserial Correlations between ME in Single Years and IM: 1992 to 2018

\begin{tabular}{|c|c|c|c|c|}
\hline ZDHS Phase & & & Education in single years & Infant Death \\
\hline \multirow[t]{4}{*}{ ZDHS1992 } & \multirow[t]{2}{*}{ ME in Single Years } & Pearson Correlation & 1 & $-.037^{\star \star}$ \\
\hline & & Sig. (2-tailed) & & .003 \\
\hline & \multirow[t]{2}{*}{ IM } & Pearson Correlation & $-.037^{\star \star}$ & 1 \\
\hline & & Sig. (2-tailed) & .003 & \\
\hline \multirow[t]{4}{*}{ ZDHS1996 } & \multirow[t]{2}{*}{ ME in Single Years } & Pearson Correlation & 1 & $-.029^{\star}$ \\
\hline & & Sig. (2-tailed) & & .013 \\
\hline & \multirow[t]{2}{*}{ IM } & Pearson Correlation & $-.029^{*}$ & 1 \\
\hline & & Sig. (2-tailed) & .013 & \\
\hline \multirow[t]{4}{*}{ ZDHS2001/02 } & \multirow[t]{2}{*}{ ME in Single Years } & Pearson Correlation & 1 & $-.027^{\star}$ \\
\hline & & Sig. (2-tailed) & & .028 \\
\hline & \multirow[t]{2}{*}{ IM } & Pearson Correlation & $-.027^{\star}$ & 1 \\
\hline & & Sig. (2-tailed) & .028 & \\
\hline \multirow[t]{4}{*}{ ZDHS2007 } & \multirow[t]{2}{*}{ ME in Single Years } & Pearson Correlation & 1 & -.006 \\
\hline & & Sig. (2-tailed) & & .642 \\
\hline & \multirow[t]{2}{*}{ IM } & Pearson Correlation & -.006 & 1 \\
\hline & & Sig. (2-tailed) & .642 & \\
\hline \multirow[t]{4}{*}{ ZDHS2013/14 } & \multirow[t]{2}{*}{ ME in Single Years } & Pearson Correlation & 1 & -.014 \\
\hline & & Sig. (2-tailed) & & .111 \\
\hline & \multirow[t]{2}{*}{ IM } & Pearson Correlation & -.014 & 1 \\
\hline & & Sig. (2-tailed) & .111 & \\
\hline \multirow[t]{4}{*}{ ZDHS2018 } & \multirow[t]{2}{*}{ ME in Single Years } & Pearson Correlation & 1 & -.005 \\
\hline & & Sig. (2-tailed) & & .594 \\
\hline & \multirow[t]{2}{*}{ IM } & Pearson Correlation & -.005 & 1 \\
\hline & & Sig. (2-tailed) & .594 & \\
\hline
\end{tabular}

Table 2 presents the correlations between ME in single years and IM from 1992 to 2001-2 and as indicated in the table, increase in ME years was associated with a decrease in IM with Point-Biserial correlation coefficients of $-.037^{\star \star},-.029^{\star}$ and $-.027^{\star}$ which were statistically significant at the $P=0.003, P=0.013$ and $P=0.028$ respectively.

\section{Multivariate Analysis}


By use of Binary Logistic Regression, three models were fitted using the ENTER method to determine the influence of ME and its interaction with the selected explanatory variables on IM. In the first model all the predictor variables were entered to determine their single general influence on IM. However, the first model is not presented in this paper because the main aim of the paper was to determine how ME related with IM and how this key independent variable with its interactions influenced IM for the period under study. In the second model, ME as a single variable and its interactions with other predictor variables were entered to determine their general interaction influence on IM. In this model however, only variables which were found to be associated with ME were included. In the third-final model, ME as a single (key independent) variable and the interactions which influenced IM throughout the period under study were entered. The goodness-of-fit of the final model was done for prediction accuracy at -2 log likelihood, Cox \& Snell R squared and Hosemer and Lemeshow tests. Results are presented with respect to the macro-variables: social-economic, demographic, mother and child health and water and sanitation factors.

\section{Second Model}

Table 3: Interaction Influence of ME and other Predictors on IM 


\begin{tabular}{|c|c|c|c|c|c|c|c|c|c|c|c|}
\hline \multirow[t]{2}{*}{ Variables in ZDHS } & \multicolumn{2}{|c|}{ ZDHS1992 } & \multicolumn{2}{|c|}{ ZDHS1996 } & \multicolumn{2}{|c|}{ ZDHS2001/2 } & \multicolumn{2}{|c|}{ ZDHS2007 } & \multicolumn{2}{|c|}{$\begin{array}{l}\text { ZDHS2013/14 } \\
\text { ZDHS2018 }\end{array}$} & \multirow[b]{2}{*}{ B } \\
\hline & B & Sig. & B & Sig. & B & Sig. & B & Sig. & B & $\begin{array}{l}\text { Sig. } \\
\text { Sig. }\end{array}$ & \\
\hline \multicolumn{12}{|l|}{ M.E / Me * Social-EC- Factors } \\
\hline ME in single years & -.21 & $.011^{*}$ & -.35 & $.031^{*}$ & -.41 & $.023^{\star}$ & -.27 & .346 & -7.10 & $\begin{array}{l}.921 \\
.100\end{array}$ & -.571 \\
\hline ME * Province & & $.000 *$ & & $.001 *$ & & $.000 *$ & & $.031^{\star}$ & & $\begin{array}{l}.019 * \\
.004^{\star}\end{array}$ & \\
\hline Copperbelt (1) & -.17 & .099 & -.04 & .703 & -.01 & .892 & -.00 & .982 & -.23 & $\begin{array}{l}.085 \\
.324\end{array}$ & -.033 \\
\hline Eastern (2) & -.24 & $.014^{\star}$ & -.13 & .153 & -.03 & .808 & -.05 & .708 & -.15 & $\begin{array}{l}.236 \\
.796\end{array}$ & -.008 \\
\hline Luapula (3) & -.07 & .459 & -.14 & .125 & -.11 & .303 & .27 & $.032^{\star}$ & .08 & $\begin{array}{l}.533 \\
.156\end{array}$ & .041 \\
\hline Lusaka (4) & .12 & .216 & .12 & .207 & .30 & $.001 *$ & .24 & .075 & -.12 & $\begin{array}{l}.360 \\
.025^{\star}\end{array}$ & -.074 \\
\hline Muchinga (5) & & & & & & & & & -.04 & $\begin{array}{l}.33 \\
.302\end{array}$ & .032 \\
\hline Northern (6) & -.03 & .740 & -.04 & .631 & .07 & .463 & .12 & .323 & -.05 & $\begin{array}{l}.763 \\
.611\end{array}$ & -.018 \\
\hline North Western (7) & -.10 & .459 & -.07 & .564 & -.16 & .239 & -.02 & .882 & .14 & $\begin{array}{l}.342 \\
.021^{\star}\end{array}$ & -.093 \\
\hline Southern (8) & -.28 & $.003^{\star}$ & -.26 & $.010 *$ & -.24 & $.027 *$ & -.01 & $.047 *$ & -.10 & $\begin{array}{l}.032^{\star} \\
.115\end{array}$ & -.051 \\
\hline Western (9) & -.24 & .062 & .01 & .879 & -.04 & .743 & -.03 & .855 & -.12 & $\begin{array}{l}.018^{\star} \\
.988\end{array}$ & -.012 \\
\hline ME by Lived in Urban (1) & .05 & .469 & .00 & .974 & -.01 & .912 & -.11 & .223 & -.06 & $\begin{array}{l}.469 \\
.385\end{array}$ & .018 \\
\hline ME by Used Contraceptive (1) & -.19 & $.001 *$ & -.22 & $.000 *$ & -.26 & $.000 *$ & -.12 & $.036 *$ & -.11 & $\begin{array}{l}.025^{\star} \\
.000^{\star}\end{array}$ & -.069 \\
\hline \multicolumn{12}{|l|}{ M.E *Demographic Factors } \\
\hline M. E* M. Age In 5-Year & & $.035^{\star}$ & & $.004^{\star}$ & & .378 & & $.022^{\star}$ & & $\begin{array}{l}.00{ }^{\star} \\
.000 \star\end{array}$ & \\
\hline$(20-24)(1)$ & -.23 & .318 & .12 & .618 & -.19 & .286 & -.24 & .274 & -.09 & $\begin{array}{l}.709 \\
.002 \star\end{array}$ & -.019 \\
\hline$(25-29)(2)$ & -.07 & .744 & .14 & .527 & -.26 & .122 & -.34 & .082 & -.41 & $\begin{array}{l}.055 \\
.001 *\end{array}$ & -.095 \\
\hline$(30-34)(3)$ & -.07 & .723 & .10 & .660 & -.13 & .444 & -.28 & .152 & -.42 & $\begin{array}{l}.046^{\star} \\
.005^{\star}\end{array}$ & -.088 \\
\hline$(35-39)(4)$ & -.07 & .738 & .06 & .794 & -.18 & .292 & -.47 & $.018^{\star}$ & -.53 & $\begin{array}{l}.013^{\star} \\
.002^{\star}\end{array}$ & -.109 \\
\hline$(40-44)(5)$ & -.18 & .390 & -.22 & .350 & -.16 & .345 & -.33 & .099 & -.53 & $\begin{array}{l}.015^{\star} \\
.118\end{array}$ & -.064 \\
\hline$(45-49)(6)$ & -.09 & .694 & -.08 & .753 & -.22 & .243 & -.26 & .229 & -.32 & $\begin{array}{l}.166 \\
.173\end{array}$ & -.122 \\
\hline ME by Pre-Birth Interval24+(1) & -.20 & $.000 *$ & -.15 & $.001 *$ & -.15 & $.002 *$ & -.09 & $.016^{\star}$ & -.15 & $\begin{array}{l}.007 * \\
.000 *\end{array}$ & -.107 \\
\hline \multicolumn{12}{|l|}{ M.E * Environmental Factors } \\
\hline ME By Sourced from Pipe (1) & -.01 & .824 & -.03 & .676 & -.02 & .810 & -.15 & .098 & -.04 & $\begin{array}{l}.612 \\
.170\end{array}$ & .052 \\
\hline ME By Flushable Toilet (1) & .07 & .205 & .06 & .294 & .04 & .662 & -.02 & .862 & .16 & $.037 \star$ & -.05 \\
\hline
\end{tabular}


.070

\begin{tabular}{|c|c|c|c|c|c|c|c|c|c|c|c|}
\hline \multicolumn{12}{|l|}{ M.E * M.C Health Factors } \\
\hline ME By Breastfed (1) & -1.49 & $.000^{*}$ & -1.82 & $.000^{*}$ & -1.81 & $.000^{*}$ & -1.66 & $.000 *$ & -7.26 & $\begin{array}{l}.019 * \\
.000^{*}\end{array}$ & -.460 \\
\hline ME By Delivered from Hospital (1) & -.09 & .077 & -.04 & .439 & -.04 & .441 & -.08 & .222 & -.00 & $\begin{array}{l}.954 \\
.067\end{array}$ & .34 \\
\hline ME By Received Antenatal Care (1) & -.23 & $.000^{*}$ & -.00 & $.02^{\star}$ & -.22 & $.000^{\star}$ & -.24 & $.000 *$ & -.05 & $\begin{array}{l}.046^{*} \\
.000^{*}\end{array}$ & -.159 \\
\hline $\begin{array}{l}\text { ME By Received Tetanus Injection } \\
\text { (1) }\end{array}$ & -.01 & .822 & -.05 & .195 & .03 & .600 & .03 & .615 & .09 & $\begin{array}{l}.188 \\
.900\end{array}$ & -.003 \\
\hline Intercept & 2.03 & $.000^{*}$ & 1.95 & $.000^{*}$ & 2.12 & $.000^{*}$ & 2.23 & $.000^{*}$ & .09 & $\begin{array}{l}.001^{*} \\
.000\end{array}$ & 3.107 \\
\hline
\end{tabular}

In table 3, the intercepts (constants) show that from 1992 to 2018 infant mortality increased by [2.0, 2.0, 2.1, 2.2 .1 and 3.1 log odds, P < 0.05 : CL: 95\%] respectively, holding all predictor variables constant.

When ME (single years) was added to the second model some reductions in the coefficients were observed compared to the first model (table 3). Results show that, overall, the interactional effect between ME and Province contributed significantly to the reduction in IM throughout the period under study. However, holding everything else constant, disaggregated effects from 1992 to 2018 shows that the interaction between ME and being in Eastern Province reduced infant mortality (the least) by [.2 log odds, P < 0.05: CL: 95\%] in 1992 only. The interaction between ME and Luapula and Lusaka Provinces increased infant mortality by [.3 log odds, P <0.05: CL: 95\%] in 2007and 2001-02 respectively. The interaction between ME and Southern Province reduced infant mortality (the most) from 1992 to $2013 / 14$ by [.3, .3, .2, .0, and .1 log odds, P < 0.05: CL: 95\%] respectively. The interaction between ME and place of residence was found to have no significant effect on IM throughout the period 1992 to 2018. Throughout the period under study, the interaction between ME and contraceptive use was found to reduce infant mortality by $[.19, .2, .2, .1, .1$ and .07 log odds, $P<0.05:$ CL: $95 \%]$ respectively.

Overall, the interaction between ME and maternal age significantly contributed to the model in 1992, 1996, 2007 and 2013/14. However, holding all other variables constant, from 1992 to 2018 the interaction between ME and maternal age group 35-39 reduced IM the most by [.5, .5 and .02 log odds, P < 0.05: CL: 95\%] in 2007, 2013-14 and 2018 respectively. The interaction between ME and maternal age groups 20-24 and 40-44 reduced IM the least by [.02 and.5 log odds, P <0.05: CL: 95\%] in 2013-14 (for age group 40-44) and 2018 (for age group 20-24) respectively. Additionally, from 1992 to 2018 , the interaction between ME and birth interval reduced IM by [.2, .2, .2, .1, .2 and .12 log odds, P < 0.05: CL: 95\%] respectively.

Holding all other variables constant, for the periods from 1992 to 2018, the interaction between ME and source of drinking water and, type of toilet facility did not significantly affect infant mortality.

From 1992 to 2018 , holding other variables constant, the interaction between ME and breastfeeding, significantly reduced infant mortality by $[1.6,1.8,1.8,1.7,7.3$ and .46 log odds, $\mathrm{P}<0.05$ : CL: 95\%] respectively. The interaction between ME and place of delivery and tetanus injection did not affect infant mortality. The interaction between ME and antenatal care, significantly reduced infant mortality by [ .2, .00, .2 .2, .1 and .16 log odds, P < 0.05: CL: 95\%] from 1992 to 2018 respectively.

\section{Third Model (Final Model)}

Table 4: Binary Logistic Regression Final Model 


\begin{tabular}{|c|c|c|c|c|c|c|c|c|c|c|c|c|}
\hline \multirow[t]{2}{*}{ Variables in ZDHS } & \multicolumn{2}{|c|}{ ZDHS1992 } & \multicolumn{2}{|c|}{ ZDHS1996 } & \multicolumn{2}{|c|}{ ZDHS2001/2 } & \multicolumn{2}{|c|}{ ZDHS2007 } & \multicolumn{2}{|c|}{ ZDHS2013/14 } & \multicolumn{2}{|c|}{ ZDHS2018 } \\
\hline & B & Sig. & B & Sig. & B & Sig. & B & Sig. & B & Sig. & B & Sig. \\
\hline \multicolumn{13}{|l|}{ ME/ M.E * Social-Economic And } \\
\hline \multicolumn{13}{|l|}{ Demographic Factors } \\
\hline ME Single Years & -.01 & $.041^{\star}$ & -.05 & $.051^{\star}$ & -.18 & $.025^{\star}$ & -.32 & .346 & -7.00 & .911 & $\begin{array}{l}-.186 \\
.120\end{array}$ & \\
\hline ME By Used Contraceptive (1) & -.65 & $.001^{\star}$ & -3.2 & $.000 *$ & -1.7 & $.000 *$ & -.62 & $.016^{*}$ & -.91 & $.025^{\star}$ & $\begin{array}{l}-.071 \\
.000\end{array}$ & \\
\hline ME By Pre-birth_Interval_24+(1) & -.80 & $.000 *$ & -.75 & $.001^{\star}$ & -.56 & $.002^{\star}$ & -.98 & $.016^{*}$ & -.57 & $.007 *$ & $\begin{array}{l}-.101 \\
.000\end{array}$ & \\
\hline \multicolumn{13}{|l|}{ M.E * Mother and Child Health And } \\
\hline \multicolumn{13}{|l|}{ Water and Sanitation Factors } \\
\hline ME By Breastfed (1) & -2.49 & $.000 *$ & -.91 & $.000 *$ & -3.81 & $.000 *$ & -1.88 & $.000 *$ & -8.62 & $.019 *$ & $\begin{array}{l}-.434 \\
.000\end{array}$ & \\
\hline $\begin{array}{l}\text { ME By Received Antenatal Care } \\
\text { (1) }\end{array}$ & -1.23 & $.000 *$ & -.07 & $.002^{\star}$ & -.72 & $.000^{*}$ & -.94 & $.000 *$ & -.65 & $.046^{\star}$ & $\begin{array}{l}-.153 \\
.000\end{array}$ & \\
\hline Intercept & 6.03 & $.000 *$ & 2.65 & $.000 *$ & .61 & $.000^{*}$ & 1.23 & $.000 *$ & .19 & $.001^{\star}$ & $\begin{array}{l}-3.111 \\
.000\end{array}$ & \\
\hline
\end{tabular}

When ME single years was added to the third-final model further reductions in the coefficients were observed compared to the coefficients in the first and second models (table 4). Variables which significantly contributed to the reduction in infant mortality throughout the period under study, (in the second model), including maternal education as the key independent variable, were advanced to the final (third) model. Table 4 shows the model with ME, ME by use of contraceptives (1), ME by preceding birth interval 24+ months (1), ME by breastfeeding (1) and ME by received antenatal care (1). Apart from ME which only influenced to the reduction in IM from 1992 to 2001-02, all the interactions in the model significantly reduced IM throughout the period under study.

\section{Goodness-of-fit of the Model}

From 1992 to 2018 model 3 illustrated $91.4 \%, 92.4 \%, 93.7 \%, 95.1 \%, 96.5 \%$ and $96.2 \%$ accuracy of data prediction, respectively. The model indicates that variations of $8.4 \%$ (Cox \& Snell R2: 0.084) 12.9\% (Cox \& Snell R2: 0.129) 14.7\% (Cox \& Snell R2: 0.147), 13.8\% (Cox \& Snell R²: 0.138), 21.2\% (Cox \& Snell R2: 0.212) and 6.9\% (Cox \& Snell R²: 0.212) correspondingly, (in IM) were explained by the model. Hosmer and Lemeshow goodness of fit model of $[.058, .098, .276, .091, .070$ and $.197(P>0.05)]$, respectively, showed that the model estimates were

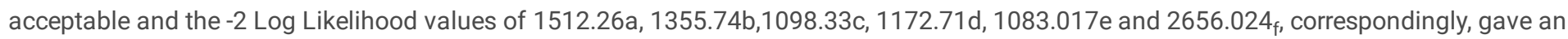
indication of a good model fit.

\section{Discussion}

To address objective one, point-biserial correlation was done between ME in single years and IM from 1992 to 2018 . It was found that ME was significantly (negatively) correlated to IM from 1992 to 2001-02. That is, increase in ME years was associated with a decrease in IM. However, the correlation coefficients were very weak negatives indicating that there is a very weak negative relationship between ME and IM. This could imply that ME has less direct effect on IM and this maybe for the reason that, education only exposes women to accessing other factors which may have more direct or indirect effects on the infants' survival. Therefore, having received education alone does not guarantee the survival of infants. These results are consistent with what other researchers argue that the relationship between ME and IM is very week when socioeconomic, environmental, community and health characteristics of mothers are controlled for. They argue that the socio-economic, environmental, community and health characteristics may be the pathways through which ME influences IM (12).

Maternal education is internationally recognized as one of the strongest determinants of infant survival in developing countries and girl child education is a common policy recommendation to improve infant health in developing countries (13). Literature shows that the education of women in Zambia has been greatly improving with more women attaining higher education in recent times compared to the past years (5). However, in this study, ME was found to be negatively associated with IM from 1992 to 2001-02 only. This confirms with the correlation results in which ME and IM were negatively related from 1992 to 2001-02. However, it was expected that ME would be negatively associated, with IM throughout the period 1992 to 2018. This scenario is in line with literature which explains that; in recent years more women, worldwide, have been attaining higher education which subsequently, makes them become very busy with economic activities and in instances where they have 
infants, their attention on their infants probably reduces as most of them would leave their infants in the hands of maids/nuns among others who may have little or no education at all. Faced with economic challenges, coupled with more widespread gender equality perspectives which have driven men away from the idea of sole responsibility for provision in homes, it has meant that women, or mothers, have less time to focus their attention and care on infants. Other women, due to their busy schedules may have little or no time to prepare nutritional sound foods for their infants (14). These results however, are in contradiction with most demographic research which shows that there is a strong statistical association between maternal education and infant mortality (10-12). Nonetheless, the results are in line with other researchers (12) who reject the existence of a strong causal relationship between ME and IM arguing that the nature of disease to which the children are exposed during the first year of life is such that mothers cannot do much in order to prevent their deaths.

Among the interactions of ME by social-economic and demographic factors, only the interactions between ME and contraceptive use and ME and preceding birth interval significantly affected IM throughout the period under study. From 1992 to 2018 , the interaction between ME and contraceptive use significantly affected IM. It is argued that educated women may know the importance of the usage of contraceptives and this allows them to have wanted children at their own convenient time and this makes them prepared psychologically physically, and financially with regards to the raising of the children. A possible explanation for this could be that significant strides have been made in the improvements in access to education for women, subsequently resulting in their knowledge of sex rights, and use of contraceptives. As such, in the recent past, the average use of contraceptives in Zambia has been improving and this is probably helping women to have health children at the right time and age (5). At the second level of analysis, maternal education was significantly associated with contraceptive use throughout the period under study. Other scholars argue that maternal education is the best contraception adding that many countries are now supporting and improving education levels of women to achieve multiple goals including the reduction in fertility levels as well as infant, and child mortality through a single policy (13-15). Education does not only increase the use of contraceptives but is itself a contraceptive technique, therefore combining it with actual contraceptive use knowledge, women will bear children at the right (safe and healthy) time, and ensure that they care for their infants wholeheartedly (16-19)

Additionally, from 1992 to 2018, the interaction between ME and birth interval Influenced the decline in IM. Educated mothers usually have fewer and well-spaced children. Smaller families help them to plan well and manage their families within their timed amounts of resources and as such their infants are usually well provided for. This can possibly be explained by the indication in the ZDHS that the average number of months for child spacing in Zambia has been increasing (5). In addition, the spacing of children of $24+$ months equally helps women to be well prepared physically, mentally and financially and this makes them be able to provide enough required care and resources for their infants $(17-19)$.

Among the interactions of ME by environmental and mother and child health factors, only the interactions between ME and breast feeding and ME and antenatal visits significantly affected IM throughout the period under study. As indicated, from 1992 to 2018 the interaction between ME and breastfeeding, significantly effected infant mortality. Educated women may have enough nutritional foods to provide their infants with and, this coupled with breastfeeding makes their infants even healthier because breast milk provides even more natural nutrition and antibodies which protects the infants from certain acute diseases. According to the 2018 data, about three-quarters (74\%) of Zambian children age 0-23 months are breastfed appropriately for their age and this includes exclusive breastfeeding for children aged 0-5 months and continued breastfeeding along with complementary foods for children age 6-23 months. About $80 \%$ of children under age 6 months are predominantly breastfed but this percentage includes children who are exclusively breastfed and those who receive breast milk and only plain water or non-milk liquids such as juice. Therefore, these factors coupled with increased education among women may explain why this interaction contributed significantly to the decline in IM. Many researchers have found similar results that breast milk is nature's perfect baby food: it contains immunity-boosting antibodies and healthy enzymes which protects against allergies and many infant diseases including virus infections among others $(21-24)$.

The interaction between ME and antenatal visit significantly influenced the decline in IM throughout the period under study. Antenatal visits help women to gather information on how best they need to care for their infants and this therefore, helps the women to provide good care for their infants. The possible explanation for this maybe that educated women know the importance of receiving antenatal care and utilize this information very well as advised by the health personnel and there is improved observable, utilization of antenatal care services in Zambia (5). During antenatal care visits various issues are addressed including HIV, the general health of the mother, and the health of the child in the womb, among others to ensure that quality health is provided for the protection of the unborn child. After delivery, women are expected to report to the hospitals for check-ups on both the mother and the infant for prevention and treatment of alarming problems (25-28). In agreement with this finding are similarly study findings of other researchers who postulate that antenatal care increases awareness of maternal and newborn health needs and self-care during pregnancy and the postnatal period, including the need for social support during and after pregnancy (29). It promotes healthy behaviors in the home, including healthy lifestyles and diet, safety and injury prevention, support and care in the home, such as advice and adherence support for preventive interventions like iron supplementation among other things (29-30). 


\section{Conclusion}

In this study a very weak negative relationship between ME and IM was found. An increase in the number of years spent in school was found to be associated with a very minimal influence on the decline in IM from 1992 to 2001-2. This may imply that ME has less direct effect on IM for the reason that education only exposes women to accessing other factors which may have more direct effects on the infants' survival. When interacted with social-economic and demographic factors it was found that only the interactions between ME and contraceptive use and, ME and preceding birth interval, ME and breastfeeding and, ME and antenatal visit (care) significantly influenced the reduction in IM from 1992 to 2018. Therefore, it can be stated that on its own, ME influenced the decline in IM to a lesser extent as evidenced by the very weak negative relationship found between the two variables. However, when interacted with contraceptive use, preceding birth interval, breastfeeding and antenatal visit (care), ME influenced the decline in IM to a larger extent. Consequently, in order to come up with more robust interventions to further reduce IM in the country, these interactions should be considered in the planning and implementation of child health programs such as the child health nutrition, national partnership for maternal, new-born and child health, child health week, Integrated Community Case Management of Childhood IIInesses, and the Support to Safe motherhood and New-born Health among others.

This study is relevant for programmes and interventions aimed at reducing IM in Zambia as it calls for factoring in ME as one of the areas of consideration during the design and implementation stages. The study contributes to demographic literature on ME and IM in Zambia and sub-Saharan Africa generally.

\section{Abbreviations}

CAMFED Campaign for Female Education

CL Confidence Level

HIV/AIDS Human Immunodeficiency Virus/Acquired Immune Deficiency Syndrome

IM Infant Mortality

ME Maternal Education

NGOs Non-Governmental Organizations

SPSS Statistical Package for Social Sciences

SSA Sub-Saharan Africa

ZDHS Zambia Demographic and Health Survey

\section{Declarations}

Ethics Approval and Consent to Participate

This study was approved by the directorate of research and graduate studies (DRGS) University of Zambia and the Demographic and Health Survey Programme. There was no individual consent required in this study because the study was pure based on secondary data.

Consent for Publication

This study did not involve direct human participants. However, consent to make publications on the secondary ZDHS data was sought from Demographic and Health Survey Programme.

Availability of Data and Materials

The six ZDHS data sets which were employed in the analyses in this study are available at the Demographic and Health Survey Programme: (https://dhsprogram.com/data/).

Competing interests

The authors declare that they have no competing interests.

Funding 
The main author had no capacity to fund the study and as such, he opted to use secondary data which was cheaper and affordable. The main expenditures on the study were on the review of literature, consultations with relevant bodies, ethical clearance and editorial works, all of which were funded through the help from family and friends.

Authors' Contributions

The main author is the pioneer and writer of the manuscript while the core author provided all the technical guidance and specialty-subject editorials/reviews to the paper.

Acknowledgements

The main author do-hereby acknowledges:

1. The core author, Dr. Mapoma (PhD) for his tireless guidance and support from conception of the research idea, to the submission of this Journal.

2. Tato Nyirenda for his contribution during data analysis.

3. Parents; Mr and Mrs Halinga for the holistic support that they rendered to me during my study.

4. The Measure Demographic and Health Survey Programme for granting me permission to use the six Zambia Demographic and Health Survey data sets for my analysis.

5. Dr Mukumbuta, Mr Mwansa sosteness, and Mr Chimponde Collins for editorial works.

6. The Almighty God for his eternal fortification and for keeping me in good health throughout my study period.

\section{References}

1. Mathews TJ, MacDorman MF, Thoma ME. Infant mortality statistics from the 2013 period linked birth/infant death data set. 2015;

2. Basumatary K. Factors Affecting Infant Mortality Rate. 2016;2(11):10.

3. WHO U, Mathers C. Global strategy for women's, children's and adolescents' health (2016-2030). Organization. 2017;2016(9).

4. Gwatkin DR, Rustein S, Johnson K, Pande RP, Wagstaff A. Socio-economic differences in health, nutrition, and population in Bangladesh, 2000. Available Online Www1 Worldbank Orgprempovertyhealthdatabangladeshbangladesh Pdfaccessed 15 July 2015.

5. Zambia Demographic and Health survey Report. Central Statistics Office; 2013.

6. Shoham-Yakubovich I, BAREL V. Maternal education as a modifier of the association between low birthweight and infant mortality. Int J Epidemiol. 1988;17(2):370-7.

7. Basu AM, Stephenson R. Low levels of maternal education and the proximate determinants of childhood mortality: a little learning is not a dangerous thing. Soc Sci Med. 2005;60(9):2011-23.

8. Huffman SL. Determinants of breastfeeding in developing countries: overview and policy implications. Stud Fam Plann. 1984;15(4):17083.

9. Pamuk ER, Fuchs R, Lutz W. Comparing relative effects of education and economic resources on infant mortality in developing countries. Popul Dev Rev. 2011;37(4):637-64.

10. Abuqamar M, Coomans D, Louckx F. The impact of parental education on infant mortality in Gaza strip, Palestine. J Public Health Epidemiol. 2011;3(1):28-33.

11. Mosley WH. Child survival: research and policy. Popul Dev Rev. 1984;10:3-23.

12. Desai S, Alva S. Maternal education and child health: Is there a strong causal relationship? Demography. 1998;35(1):71-81.

13. Hannum E, Buchmann C. Global educational expansion and socio-economic development: An assessment of findings from the social sciences. World Dev. 2005;33(3):333-54.

14. Kayigamba C. Determinants of infant mortality in Rwanda [PhD Thesis]. University of NAIROBI; 2009.

15. Boehmer U, Williamson JB. The impact of women's status on infant mortality rate: A cross-national analysis. Soc Indic Res. 1996;37(3):333-60.

16. Mason KO. The impact of women's social position on fertility in developing countries. In: Sociological forum. Springer; 1987. p. $718-45$.

17. Craig AL. "Quality is everything": rhetoric of the transatlantic birth control movement in interwar women's literature of England, Ireland and the United States [PhD Thesis]. 2009.

18. Miller JE, Trussell J, Pebley AR, Vaughan B. Birth spacing and child mortality in Bangladesh and the Philippines. Demography. 1992;29(2):305-18. 
19. Nath DC, Land KC, Singh KK. Birth spacing, breastfeeding, and early child mortality in a traditional Indian society: a hazards model analysis. Soc Biol. 1994;41(3-4):168-80.

20. Norton M. New evidence on birth spacing: promising findings for improving newborn, infant, child, and maternal health. Int $\mathrm{J}$ Gynecol Obstet. 2005;89:S1-6.

21. Rubin JS. The Maker's diet. Charisma Media; 2005.

22. Saputo L, Faass N. Boosting Immunity: Creating Wellness Naturally. New World Library; 2010.

23. Stengler M. Nature's Virus Killers. M. Evans; 2001.

24. Thomas P. Healthy, Happy Baby: The Essential Guide to Raising a Toxin-free Baby. Pan Macmillan; 2008.

25. Mathole T, Lindmark G, Majoko F, Ahlberg BM. A qualitative study of women's perspectives of antenatal care in a rural area of Zimbabwe. Midwifery. 2004;20(2):122-32.

26. Nyblade L, Field ML. Women, communities, and the prevention of mother-to-child transmission of HIV: issues and findings from community research in Botswana and Zambia. Wash DC Int Cent Res Women. 2000;

27. Organization WH. Women's health: towards a better world, report of the First Meeting of the Global Commission on Women's Health, 13-15 April 1994, Geneva, Switzerland. World health organization; 1994.

28. Varga C, Brookes H. Factors influencing teen mothers' enrollment and participation in prevention of mother-to-child HIV transmission services in Limpopo Province, South Africa. Qual Health Res. 2008;18(6):786-802.

29. Ali R. Global Women's Health (GWH).

30. Ali R. Global Women's Health (GWH).

31. Chan KP. Effects of perinatal meditation on pregnant Chinese women in Hong Kong: a randomized controlled trial. J Nurs Educ Pract. 2015;5(1):1-18.

32. Faso B. Testing Approaches for Increasing Skilled Care During Childbirth: Key Findings from Ouargaye, Burkina Faso. 2007;

\section{Figures}

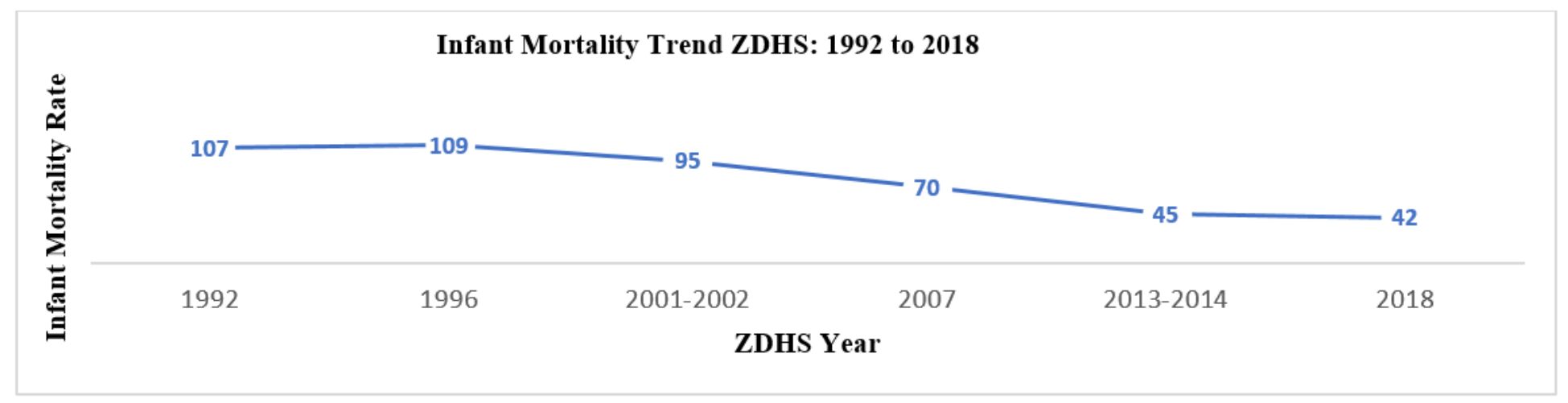

\section{Figure 1}

Infant Mortality Trend: Zambia (ZDHS: 1992 to 2018) 